\title{
SEMINORM PADA RUANG FUNGSI TERINTEGRAL DUNFORD
}

\author{
Solikhin $^{1 *}$, YD Sumanto ${ }^{1}$, Abdul Aziz ${ }^{1}$ \\ ${ }^{1}$ Departemen Matematika, FSM Universitas Diponegoro \\ Jl. Prof. Soedarto, S.H. Semarang \\ *Corresponding Author's Email : solikhin@live.undip.ac.id
}

\begin{abstract}
This article discussed the seminorm on Dunford integrable functional space. We show that the set of all Dunford integrable functions is linear space. The results were shown that $(D[a, b],\|\cdot\|)$ is a seminorm space with function defined by $\|f\|=\sup _{\substack{x^{*} \in X^{*} \\ \| x^{*} \mid \leq 1}}\left\{\sup _{E \in[a, b] \mid}\left|(L) \int_{E} x^{*} f\right|\right\}$. Furthermore, $(D[a, b], d)$ is a pseudomatrix space with

function defined by $d(f, g)=\|f-g\|=\sup _{\substack{x^{*} \in X^{*} \\ \| x^{*} \mid \leq 1}}\left\{\sup _{E \subset[a, b] \mid}\left|(L) \int_{E} x^{*}(f-g)\right|\right\}$.
\end{abstract}

Keywords: Dunford integral, seminorm, pseudomatrix.

Abstrak. Pada artikel ini dibahas seminorm pada ruang fungsi terintegral Dunford.
Ditunjukkan bahwa koleksi semua fungsi yang terintegral Dunford merupakan ruang
linear. Selanjutnya $(D[a, b],\|\cdot\|)$ merupakan ruang seminorma terhadap seminorma
$\|f\|=\sup _{\substack{x^{*} * X^{*} \\ \| x^{*} \mid \leq 1}}\left\{\sup _{E \subset[a, b] \mid}\left|(L) \int_{E} x^{*} f\right|\right\}$ dan $(D[a, b], d)$ merupakan ruang pseudometrik terhadap
pseudometrik $d(f, g)=\|f-g\|=\sup _{\substack{x^{*} \in *^{*} \\\left\|x^{*}\right\| \leq 1}}\left\{\sup _{E \subset[a, b] \mid}\left|(L) \int_{E} x^{*}(f-g)\right|\right\}$.

Kata kunci: Integral Dunford, seminorma, pseudometrik.

\section{PENDAHULUAN}

Integral dari suatu fungsi non-negatif satu variabel atau dua variabel pada prinsipnya dianggap sebagai luas daerah atau volume di bawah kurva. Misalnya untuk fungsi kontinu pada interval terbatas, maka luas daerah atau volume di bawah kurva dapat didefinisikan sebagai integral. Integral ini dihitung dengan menggunakan aproksimasi atau menggunakan teorema dasar kalkulus asalkan mempunyai anti-derivatif. Integral semacam ini dinamakan integral deskriptif atau integral Newton [1]. Akan tetapi tidak semua fungsi mempunyai anti-derivatif, maka proses pengintegralannya secara kontruktif yang dibangun berdasarkan partisi seperti integral Riemann $[1,2]$.

Integral Riemann didefinisikan berdasarkan partisi, kontruksi urutan area di bawah kurva yang berbentuk persegi panjang vertikal yang mudah dihitung dari fungsi yang diberikan. Definisi integral ini telah berhasil memberikan jawaban untuk berbagai permasalahan yang diberikan. Akan tetapi, integral Riemann tidak berinteraksi dengan baik dengan mengambil 
batas urutan fungsi. Untuk kelas fungsi yang lebih luas misalkan fungsi Dirichlet, integral Riemann tidak mampu memberikan hasil.

Integral Lebesgue dapat menjawab permasalahan yang tidak adapat diselesaikan oleh integral Riemann. Integral Lebesgue memungkinkan untuk menghitung integral dari kelas fungsi yang lebih luas, misalnya seperti fungsi Dirichlet. Fungsi Dirichlet ini terintegral Lebesgue dengan nilai nol. Integral ini juga memperluas domain untuk fungsi-fungsi yang dapat didefinisikan. Secara analisis, integral Lebesgue didefinisikan berdasarkan fungsi sederhana pada sebarang himpunan terukur $E$ untuk fungsi bernilai real $R$.

Pada banyak penerapan, misalnya dalam persamaan differensial, optimasi dan lain sebagainya tidak menutup kemungkinan permasalahan integral dihadapkan pada fungsi bernilai Banach $X$. Misalnya seperti integral Bochner dan integral Dunford [3]. Fungsi $f: I \rightarrow X$ dikatakan terintegral Bochner jika terdapat barisan fungsi sederhana $\left(f_{n}\right)$ sehingga

$\lim _{n \rightarrow \infty} \int_{I}\left\|f_{n}-f\right\| d \mu=0$. Sedangkan fungsi terukur lemah $f$ dikatakan terintegral Dunford, jika untuk setiap $x^{*} \in X^{*}\left(X^{*}\right.$ adalah ruang dual dari ruang Banach $X$ ) fungsi bernilai real $x^{*}(f)$ terintegral Lebesgue [3].

Jaminan adanya nilai integral Dunford adalah Lemma Dunford [3]. Lemma ini mengkontruksi adanya operator linear kontinu. Kemudian berdasarkan lemma tersebut dikaji integral Dunford beserta sifat-sifat sederhananya. Dikaji juga sifat daripada operatornya [3, 4]. Selanjutnya didefinisikan sebuah fungsi pada ruang fungsi terintegral Dunford. Diselidiki apakah fungsi tersebut merupakan norma atau seminorma, lebih lanjut berdasarkan fungsi tersebut didefinisikan fungsi jarak. Diselidiki apakah fungsi jarak tersebut merupakan metrik atau pseudometrik pada runag fungsi terintegral Dunford.

\section{RUANG METRIK DAN RUANG BERNORMA}

Diberikan definisi ruang metrik dan ruang bernorma beserta sifat-sifatnya.

Definisi 2.1 [5] Diberikan himpunan $X$. Fungsi jarak $d: X \times X \rightarrow R$ dikatakan metrik pada $X$ jika memenuhi

(M1). $d(x, y) \geq 0$, untuk setiap $x, y \in X$

(M2). $d(x, y)=0 \Leftrightarrow x=y$,

(M3). $d(x, y)=d(y, x)$, untuk setiap $x, y \in X$ dan

(M4). $d(x, y) \leq d(x, z)+d(y, z)$, untuk setiap $x, y, z \in X$.

Himpunan $X$ yang dilengkapi dengan metrik $d$ dinamakan ruang metrik, dinotasikan $(X, d)$ . Jika kondisi (M2) tidak terpenuhi, maka fungsi jarak $d$ dikatakan psedometrik.

Definisi 2.2 [5] Barisan $\left(x_{n}\right) \subset X$ pada ruang metrik $(X, d)$ dikatakan konvergen jika ada $x \in X$ sehingga 


$$
\lim _{n \rightarrow \infty} d\left(x_{n}, x\right)=0 .
$$

Sedangkan barisan $\left(x_{n}\right) \subset X$ pada ruang metrik $(X, d)$ dikatakan barisan Cauchy jika untuk setiap $\varepsilon>0$ terdapat bilangan asli $n_{0}=n_{0}(\varepsilon)$ sehingga untuk setiap $m, n \geq n_{0}$ berlaku

$$
d\left(x_{n}, x_{m}\right)<\varepsilon .
$$

Ruang metrik $(X, d)$ dikatakan lengkap jika setiap barisan Cauchy di $X$ adalah konvergen di $X$. Selanjutnya, setiap barisan konvergen pada ruang metrik merupakan barisan Cauchy.

Teorema 2.3 [6] Setiap barisan konvergen pada ruang metrik $(X, d)$ adalah barisan Cauchy.

Bukti: Diambil sebarang barisan $\left(x_{n}\right) \subset X$ yang konvergen ke $x \in X$. Berarti untuk setiap $\varepsilon>0$ terdapat $n_{0}=n_{0}(\varepsilon)$ sehingga untuk setiap $n \geq n_{0}$ berlaku

$$
d\left(x_{n}, x\right)<\frac{\varepsilon}{3}
$$

Jadi, untuk setiap $m, n \geq n_{0}$ berlaku

$$
d\left(x_{n}, x_{m}\right) \leq d\left(x_{n}, x\right)+d\left(x, x_{m}\right)<\frac{\varepsilon}{3}+\frac{\varepsilon}{3}<\varepsilon .
$$

Terbukti bahwa $\left(x_{n}\right) \subset X$ merupakan barisan Cauchy.

Definisi 2.4 [5] Diberikan $X$ ruang vektor (ruang linear). Fungsi $\|\cdot\|: X \rightarrow R$ dikatakan norma pada $X$ jika memenuhi

(N1). $\|x\| \geq 0,\|x\|=0 \quad \Leftrightarrow \quad x=\theta$,

(N3). $\|u x\|=|u|\|x\|$, dan

(N4). $\|x+y\| \leq\|x\|+\|y\|$,

untuk setiap $x, y \in X$ dan sebarang skalar $u \in R$.

Pasangan $(X,\|\cdot\|)$ dikatakan ruang bernorma jika fungsi $\|\cdot\|$ merupakan norma pada $X$. Jika pada kondisi (N1) tidak terpenuhi untuk $\|x\|=0 \Rightarrow x=\theta$, maka fungsi $\|\cdot\|$ merupakan seminorma. Norma pada $X$ dapat mendefinisikan sebuah metrik $d$ pada $X$ yang diberikan oleh

$$
d(x, y)=\|x-y\|,
$$

untuk setiap $x, y \in X$ dan disebut metrik yang diinduksi oleh norma. 
Definisi 2.5 [5] Diberikan $(X,\|\cdot\|)$ ruang bernorma. Barisan $\left(x_{n}\right)$ dikatakan konvergen jika ada $x \in X$ sehingga

$$
\lim _{n \rightarrow \infty}\left\|x_{n}-x\right\|=0 \text {. }
$$

Sedangkan barisan $\left(x_{n}\right)$ dikatakan barisan Cauchy jika untuk setiap $\varepsilon>0$ terdapat $n_{0}$ sehingga untuk setiap $n, m \geq n_{0}$ berlaku

$$
\left\|x_{n}-x_{m}\right\|<\varepsilon
$$

Selanjutnya, jika setiap barisan Cauchy pada ruang bernorma $(X,\|\cdot\|)$ konvergen di $X$ maka $(X,\|\cdot\|)$ dikatakan ruang Banach, yaitu ruang bernorma yang lengkap.

\section{INTEGRAL DUNFORD}

Berdasarkan Lemma Dunford, maka dapat didefinisikan integral Dunford sebagai berikut.

Definisi 3.1 [3] Diketahui $X$ ruang Banach. Fungsi $f:[a, b] \rightarrow X$ dikatakan terintegral Dunford pada $[a, b]$, ditulis $f \in D[a, b]$, jika untuk setiap $x^{*} \in X^{*}$ fungsi $x^{*}(f)$ terintegral Lebesgue pada $[a, b]\left(x^{*}(f) \in L[a, b]\right)$ dan untuk setiap himpunan terukur $E \subset[a, b]$ terdapa vektort $x_{(f, E)}^{* *} \in X^{* *}$ sehingga

$$
x_{(f, E)}^{* *}\left(x^{*}\right)=(L) \int_{E} x^{*}(f),
$$

untuk setiap $x^{*} \in X^{*}$.

Nilai integral Dunford $(D) \int_{E} f$, fungsi $f$ atas himpunan terukur $E \subset[a, b]$ diberikan oleh $x_{(f, E)}^{* *} \in X^{* *}$, yaitu

$$
x_{(f, E)}^{* *}=(D) \int_{E} f,
$$

adalah tunggal.

Teorema 3.2 [4] Jika $f \in D[a, b]$, maka untuk setiap himpunan terukur $E \subset[a, b]$ vektor $x_{(f, E)}^{* *} \in X^{* *}$ tunggal.

Bukti: Diambil sebarang himpunan terukur $E \subset[a, b]$. Andaikan terdapat vektor $x_{(f, E)}^{* *} \in X^{* * *}$ dan $y_{(f, E)}^{* *} \in X^{* * *}$ maka

$$
x_{(f, E)}^{* *}\left(x^{*}\right)=(L) \int_{E} x^{*}(f) \text { dan } y_{(f, A)}^{* *}\left(x^{*}\right)=(L) \int_{E} x^{*}(f) .
$$

Lebih lanjut

$$
x_{(f, E)}^{* *}\left(x^{*}\right)-y_{(f, E)}^{* *}\left(x^{*}\right)=(L) \int_{E} x^{*}(f)-(L) \int_{E} x^{*}(f)=0, \forall x^{*} \in X^{*} .
$$


Contoh fungsi yang terintegral Dunford misalnya adalah fungsi konstan, fungsi terintegral Riemann, fungsi terintegral Lebesgue [4], atau fungsi yang terintegral McShane. Menurut Definisi 3.1 jelas bahwa jika fungsi $f$ terintegral Dunford, maka untuk setiap $x^{*} \in X^{*}$ fungsi bernilai real $x^{*} f$ terintegral Lebesgue, artinya jika untuk setiap $x^{*} \in X^{*}$ fungsi bernilai real $x^{*} f$ terintegral Lebesgue, maka $f$ terintegral Dunford.

Teorema 3.3 Fungsi $f \in D[a, b]$ jika dan hanya jika untuk setiap $x^{*} \in X^{*}, x^{*} f \in L[a, b]$.

Bukti: Jelas menurut Definisi.

Berdasarkan Definisi 3.1 dan Teorema 3.3, maka koleksi semua fungsi yang terintegral Dunford merupakan ruang linear.

Teorema 3.4 $D[a, b]$ dalah ruang linear.

Bukti: Koleksi $D[a, b]$ dikatakan ruang linear jika untuk setiap $f, g \in D[a, b]$ dan sebarang $u \in R$ berlaku $f+g \in D[a, b]$ dan $u f \in D[a, b]$.

Diambil sebarang $f, g \in D[a, b]$ dan sebarang skalar $u \in R$. Karena $f, g \in D[a, b]$, maka untuk setiap $x^{*} \in X^{*}$ diperoleh $x^{*} f \in L[a, b]$ dan $x^{*} g \in L[a, b]$. Oleh karena itu, untuk setiap $x^{*} \in X^{*}$ diperoleh $x^{*}(f+g) \in L[a, b]$. Jadi, $f+g \in D[a, b]$.

Lebih lanjut, untuk sebarang skalar $u \in R$ dan untuk setiap $x^{*} \in X^{*}$ diperoleh fungsi $x^{*}(u f) \in L[a, b]$. Jadi, uf $\in D[a, b]$.

Jadi, $D[a, b]$ ruang linier.

Teorema 3.5 Jika $f=\theta$ hampir dimana-mana pada $[a, b]$, maka $f \in D[a, b]$ dan jika $E \subset[a, b]$ himpunan terukur maka

$$
x_{(f, E)}^{* *}=\theta \text {. }
$$

Bukti: Karena $f=\theta$ hampir dimana-mana pada $[a, b]$, maka ada himpunan terukur $E \subset[a, b]$ dengan $\mu_{\alpha}(E)=0$ sehingga jika $x^{*} \in X^{*}$ berlaku

$$
x^{*} f(x)\left\{\begin{array}{l}
=0, x \in[a, b]-E \\
\neq 0, x \in E
\end{array} .\right.
$$

Dibentuk $E=\bigcup_{k=1}^{\infty} E_{k}$ dengan $E_{k}=\{x \in E: k-1 \leq\|f(x)\| \leq k, k=1,2,3, \ldots\} \subset E$ dan $\mu_{\alpha}\left(E_{k}\right)=0$

Diambil sebarang $\varepsilon>0$, maka untuk suatu $k$ terdapat himpunan terbuka $O_{k}$ dengan $\mu_{\alpha}\left(O_{k}\right)<\frac{\varepsilon}{k 2^{k}}$ sehingga $O_{k} \supset E_{k}$.

Didefinisikan fungsi positif $\delta$ pada $[a, b]$ sedemikian sehingga $N(x, \delta(x)) \subset O_{k}$ untuk $x \in E_{k}$ , $k=1,2,3, \ldots$ dan sebarang fungsi positif untuk $x$ yang lain.

Oleh karena itu, untuk sebarang $E \subset[a, b]$ himpunan terukur berlaku

$$
\left|\int_{E} x^{*}(f)-0\right|=\left|\int_{x \in E_{k}} x^{*}(f)+\int_{x \notin E_{k}} x^{*}(f)\right|=\left|\int_{x \in E_{k}} x^{*}(f)\right|<\sum_{k=1}^{\infty}\left\|x^{*}\right\| k \frac{\varepsilon}{2^{k} k}=\varepsilon
$$


untuk setiap $x^{*} \in X^{*}$ dan $\left\|x^{*}\right\| \leq 1$.

Hal ini berarti $x^{*} f \in L[a, b]$ dan untuk himpunan terukur $E \subset[a, b]$ terdapat vektor $x_{(f, E)}^{* *} \in X^{* *}$ sehingga

$$
x_{(f, E)}^{* *}\left(x^{*}\right)=(L) \int_{A} x^{*} f=0 .
$$

Jadi $f \in D[a, b]$ dan $x_{(f, E)}^{* *}=\theta$.

\section{SEMINORM PADA RUANG FUNGSI TERINTEGRAL DUNFORD}

Fungsi $f$ dan $g$ dikatakan ekuivalen, jika $f=g$ hampir dimana-mana pada $[a, b]$, yaitu jika terdapat himpunan terukur- $\alpha E \subset[a, b]$ dengan $\mu_{\alpha}(E)=0$ sehingga

$$
f(x)=g(x),
$$

untuk setiap $x \in[a, b]-E$.

Teorema 3.4 menunjukkan bahwa koleksi semua fungsi yang terintegral Dunford pada $[a, b]$ merupakan ruang linear. Selanjutnya akan didefinisikan sebuah fungsi dari $D[a, b]$ ke himpunan semua bilangan real $R$.

Definisi 4.1 Diberikan ruang linear $D[a, b]$. Didefinisikan fungsi $\|\cdot\|: D[a, b] \rightarrow R$ oleh

$$
\|f\|=\sup _{\substack{x^{*} \in X^{*} \\\left\|x^{*}\right\| \leq 1}}\left\{\sup _{E \subset[a, b] \mid}\left|(L) \int_{E} x^{*} f\right|\right\}
$$

untuk setiap $f \in D[a, b]$.

Berdasarkan Definisi 3.1, ternyata fungsi yang didefinisikan dari $D[a, b]$ ke himpunan semua bilangan real $R$ merupakan seminorm pada $D[a, b]$ seperti pada teorema berikut.

Teorema 4.2 Diberikan ruang linear $D[a, b]$. Pasangan $(D(a, b),\|\|$.$) merupakan ruang$ seminorma terhadap

$$
\|f\|=\sup _{\substack{x^{*} \in X^{*} \\\left\|x^{*}\right\| \leq 1}}\left\{\sup _{E \subset[a, b]}\left|(L) \int_{E} x^{*} f\right|\right\} .
$$

Bukti: Dibuktikan bahwa fungsi $\|\cdot\|$ merupakan seminorma pada ruang linear $D[a, b]$.

(N1). Diambil sebarang $f \in D[a, b]$.

Karena untuk setiap $x^{*} \in X^{*}$ dan $E \subset[a, b]$ berlaku $\left|(L) \int_{E} x^{*} f\right| \geq 0$, maka

$$
\|f\|=\sup _{\substack{x^{*} \in X^{*} \\\left\|x^{*}\right\| \leq 1}}\left\{\sup _{A \subset[a, b] \mid}\left|(L) \int_{A} x^{*} f\right|\right\} \geq 0 .
$$

Jadi, $\|f\| \geq 0$. 
Jika $f=\theta$ pada $[a, b]$ maka $f(x)=\theta, \forall x \in[a, b]$, sehingga untuk setiap himpunan terukur $E \subset[a, b]$ berlaku

$$
f(x)=\theta, \forall x \in E \subset[a, b] .
$$

Hal ini berakibat untuk setiap $x^{*} \in X^{*}$ dengan $\left\|x^{*}\right\| \leq 1$ diperoleh

$$
x^{*} f(x)=0, \forall x \in E \subset[a, b] .
$$

sehingga

$$
\begin{aligned}
& \Rightarrow(L) \int_{E} x^{*} f=0, \forall x^{*} \in X^{*},\left\|x^{*}\right\| \leq 1, \forall x \in E \subset[a, b] \\
& \Rightarrow\left|(L) \int_{E} x^{*} f\right|=0, \forall x^{*} \in X^{*},\left\|x^{*}\right\| \leq 1, \forall x \in E \subset[a, b] \\
& \Rightarrow \quad \sup _{x \in E}\left|(L) \int_{E} x^{*} f\right|=0 \\
& \Rightarrow \sup _{\substack{*^{*} * X^{*} \\
\left\|x^{*}\right\| \leq 1}}\left\{\sup _{E \subset a, b] \mid}\left|(L) \int_{E} x^{*} f\right|\right\}=0 \\
& \Rightarrow\|f\|=0 .
\end{aligned}
$$

Jadi jika $f=\theta$ maka $\|f\|=0$.

(N2). Diambil sebarang $f \in D[a, b]$ dan sebarang skalar $k \in R$, diperoleh

$$
\begin{aligned}
&\|k f\|=\sup _{\substack{x^{*} \in X^{*} \\
\left\|x^{*}\right\| \leq 1}}\left\{\sup _{E \subset[a, b]}\left|(L) \int_{E} x^{*}(k f)\right|\right\} \\
&= \sup _{\substack{x^{*} \in X^{*} \\
\left\|x^{*}\right\| \leq 1}}\left\{\sup _{E \subset[a, b]}|k|\left|(L) \int_{E} x^{*} f\right|\right\} \\
&=|k| \sup _{\substack{x^{*} \in X^{*} \\
\left\|x^{*}\right\| \leq 1}}\left\{\sup _{E \subset[a, b]}\left|(L) \int_{E} x^{*} f\right|\right\} \\
&=|k|\|f\| .
\end{aligned}
$$

(N3). Diambil sebarang $f, g \in D[a, b]$ diperoleh

$$
\begin{aligned}
\|f+g\| & =\sup _{\substack{x^{*} \in X^{*} \\
\left\|x^{*}\right\| \leq 1}}\left\{\sup _{E \subset[a, b]}\left|(L) \int_{E} x^{*}(f+g)\right|\right\} \\
& =\sup _{\substack{x^{*} \in X^{*} \\
\left\|x^{*}\right\| \leq 1}}\left\{\sup _{E \subset[a, b]}\left|(L) \int_{E} x^{*} f+(L) \int_{E} x^{*} g\right|\right\}
\end{aligned}
$$

Karena

$$
\sup _{E \subset[a, b]}\left\{\left|(L) \int_{E} x^{*} f+(L) \int_{E} x^{*} g\right|\right\} \leq \sup _{E \subset[a, b]}\left\{\left|(L) \int_{E} x^{*} f\right|\right\}+\sup _{E \subset[a, b]}\left\{\left|(L) \int_{E} x^{*} g\right|\right\}
$$


Maka untuk setiap $x^{*} \in X^{*},\left\|x^{*}\right\| \leq 1$ berlaku

$$
\sup _{\substack{x^{*} \in X^{*} \\\left\|x^{*}\right\| \leq 1}}\left\{\sup _{E \subset[a, b]}\left\{\left|(L) \int_{E} x^{*} f+(L) \int_{E} x^{*} g\right|\right\}\right\} \leq \sup _{\substack{x^{*} \in X^{*} \\\left\|x^{*}\right\| \leq 1}}\left\{\sup _{E \subset[a, b] \mid}\left|(L) \int_{E} x^{*} f\right|\right\}+\sup _{\substack{x^{*} \in X^{*} \\\left\|x^{*}\right\| \leq 1}}\left\{\sup _{E \subset[a, b] \mid}\left|(L) \int_{E} x^{*} g\right|\right\}
$$

Jadi,

$$
\|f+g\| \leq\|f\|+\|g\|
$$

Terbukti bahwa $(D(a, b),\|\cdot\|)$ merupakan ruang bernorma terhadap norma

$$
\|f\|=\sup _{\substack{x^{*} \in X^{*} \\\left\|x^{*}\right\| \leq 1}}\left\{\sup _{A \subset[a, b] \mid}\left|(L) \int_{A} x^{*} f\right|\right\} \text {. }
$$

Selanjutnya berdasarkan seminorma seperti pada Definisi 4.1 didefinisikan fungsi jarak pada ruang linear $D[a, b]$.

Definisi 4.3 Didefinisikan fungsi $d: D[a, b] \times D[a, b] \rightarrow R$ oleh

$$
d(f, g)=\|f-g\|
$$

untuk setiap $f, g \in H D[a, b]$.

Fungsi $d: D[a, b] \times D[a, b] \rightarrow R$ seperti pada Definisi 4.3 merupakan pseudometrik pada $D[a, b]$.

Teorema 4.4 Ruang linear $D[a, b]$ merupakan ruang pseudometrik terhadap fungsi jarak

$$
d(f, g)=\|f-g\|,
$$

untuk setiap $f, g \in D[a, b]$.

\section{Bukti:}

(D1). Diambil sebarang dua fungsi $f, g \in D[a, b]$, diperoleh

$$
d(f, g)=\|f-g\| \geq 0 .
$$

(D2). Diambil sebarang dua fungsi $f, g \in D[a, b]$, diperoleh

$$
d(f, g)=\|f-g\|=\|g-f\|=d(g, f) .
$$

(D3). Diambil sebarang tiga fungsi $f, g, h \in D[a, b]$, diperoleh

$$
d(f, h)=\|f-h\|=\|f-g+g-h\| \leq\|f-g\|+\|g-h\|=d(f, g)+d(g, h) .
$$

Jadi, fungsi $d$ merupakan pseudometrik pada $D[a, b]$.

\section{PENUTUP}

Koleksi semua fungsi yang terintegral Dunford merupakan ruang linear dan jika diberikan fungsi $\|\cdot\|: D[a, b] \rightarrow R$ oleh $\|f\|=\sup _{\substack{x^{*} \in X^{*} \\\left\|x^{*}\right\| \leq 1}}\left\{\sup _{E \subset[a, b]}\left|(L) \int_{E} x^{*} f\right|\right\}$, maka $(D[a, b],\|\cdot\|)$ merupakan ruang seminorma. Selanjutnya terhadap fungsi jarak 
$d(f, g)=\|f-g\|=\sup _{\substack{x^{*} \in X^{*} \\\left\|^{*}\right\| \leq 1}}\left\{\sup _{E \subset[a, b] \mid}\left|(L) \int_{E} x^{*}(f-g)\right|\right\}, \quad$ maka $(D[a, b], d)$ merupakan ruang psudometrik.

\section{DAFTAR PUSTAKA}

[1] Lee P.Y. (1989), Lanzhou Lectures on Henstock Integration, World Scientific, Singapore.

[2] Gordon, R.A. (1994), The Integral of lebesgue, Denjoy, Perron, and Henstock, Mathematical Society, USA.

[3] Schwabik, S., Guoju, Ye. (2005), Topics in Banach Space Integration, World Scientific, Singapore.

[4] Solikhin, dkk. (2018). Operator pada Ruang Fungsi Terintegral Dunford, Journal of Fundamental Mathematics and Application (JFMA), 2(1): 110, 10.14710/jfma.v1i2.17

[5] Kreyszig, E. (1989), Introductory Funtional Analysis with Applications, John Willey \& Sons, USA.

[6] Darmawijaya, S. (2007), Pengantar Analisis Abstrak, Jurusan Matematika Fakultas MIPA Universitas Gadjah Mada, Yogyakarta. 